\title{
Correction to: Iron metabolism in diabetes-induced Alzheimer's disease: a focus on insulin resistance in the brain
}

Ji Yeon Chung $\cdot$ Hyung-Seok Kim $\cdot$ Juhyun Song $(\mathbb{D}$

Published online: 17 September 2018

(C) The Author(s) 2018

Correction to: Biometals (2018) 31:705-714

https://doi.org/10.1007/s10534-018-0134-2

Due to a technical error, the copyright line of the above mentioned article was incorrect. The original publication has been corrected.
Open Access This article is distributed under the terms of the Creative Commons Attribution 4.0 International License (http:// creativecommons.org/licenses/by/4.0/), which permits unrestricted use, distribution, and reproduction in any medium, provided you give appropriate credit to the original author(s) and the source, provide a link to the Creative Commons license, and indicate if changes were made.

The original article can be found online at

https://doi.org/10.1007/s10534-018-0134-2.

J. Y. Chung

Department of Neurology, Chosun University School of

Medicine and Hospital, Gwangju 61452, South Korea

H.-S. Kim ( ()

Department of Forensic Medicine, Chonnam National University Medical School, Gwangju 61469, South Korea e-mail: veritas@jnu.ac.kr

\section{J. Song $(\bowtie)$}

Department of Anatomy, Chonnam National University Medical School, Gwangju 61469, South Korea

e-mail: juhyunsong@chonnam.ac.kr 